\title{
Copper corrosion protection in neutral media by dicarboxylic acid salts
}

\author{
Yu.I. Kuznetsov, I.A. Kuznetsov* and D.B. Vershok \\ A.N. Frumkin Institute of Physical Chemistry and Electrochemistry, Russian Academy of \\ Sciences, Leninsky pr. 31, 119071 Moscow, Russian Federation \\ *E-mail: anarenen@gmail.com
}

\begin{abstract}
Sodium succinate and a mixture of alkenylsuccinic sodium salts with the number of carbon atoms in the alkenyl $n_{\mathrm{c}}=12-15$ (SKAP-25) were studied as copper corrosion inhibitors (CI). It was shown that sodium succinate, despite the high hydrophilicity of its anion, can be an inhibitor of copper anodic dissolution in borate buffer ( $\mathrm{pH} 7.4$ ) containing $10 \mathrm{mmol} \mathrm{NaCl}$. It decreases the value of passivation current density $i_{\mathrm{p}}$ and increases the potential of local depassivation $E_{\mathrm{ld}}$. More hydrophobic succinate derivatives, SKAP-25, even more clearly show the properties of copper CI, decreasing $i_{\mathrm{p}}$ and significantly increasing $E_{\mathrm{ld}}$ in the same solution at lower concentrations, $C_{\text {in }} \geq 0.17 \mathrm{mmol} / \mathrm{L}$. However, comparison of copper anodic polarization curves obtained in a solution of more hydrophobic sodium tridecanoate $\left(n_{\mathrm{c}}=12\right)$ and SKAP-25 showed better alkylcarboxylate efficiency in stabilizing the passive state of copper. In this regard, the SKAP-25 anions are closer to the anions of the known CI, sodium oleate, which also contains a double bond. The efficiency of copper passivation by aqueous solutions of SKAP-25, sodium oleate and sodium tridecanoate in a humid atmosphere with daily condensation of moisture on the samples is compared. In the case where corrosive chlorides are absent, treatment with SKAP-25 turned out to be more effective. However, if after copper passivation, samples were immersed for $10 \mathrm{~s}$ in water containing $1 \mathrm{~g} / \mathrm{L} \mathrm{NaCl}$, the protective properties of SKAP-25 became weaker than those of sodium tridecanoate. In order to enhance copper protection by SKAP-25 anions in the presence of chlorides, we studied the behavior of copper by electrochemical impedance spectroscopy (EIS) in 3.5\% $\mathrm{NaCl}$ solution, without and with addition of SKAP-25 and 2-mercaptobenzothiazole sodium salt (S2-MBT) whose protective effect is due to the formation of a sparingly soluble complex with $\mathrm{Cu}(\mathrm{I})$. It was shown that very small additives of S2-MBT sharply enhanced the protective effect of SKAP-25, moreover, a blend of these CIs can be more effective than S2-MBT itself, which is poorly soluble in neutral media. The efficiency criterion is the S2-MBT coating resistance value, which is calculated from the selected equivalent electrical circuit.
\end{abstract}

Keywords: copper corrosion, copper protection, carboxylic acids, dicarboxylic acids, EIS, copper corrosion inhibitors, electrochemistry.

Received: October 21, 2019. Published: November 21, 2019

doi: $\underline{10.17675 / 2305-6894-2019-8-4-13}$ 


\section{Introduction}

Copper and its alloys are important structural materials and are used in many industries. Pipes for transporting liquids and gases, heat exchangers, wires and other components of electrical equipment, radio equipment and microelectronics are made of this. Due to its high thermal and electrical conductivity, copper is currently used in renewable energy systems. Copper and some of its alloys are used in art, for example, in jewelry, and as a material for monuments. Despite the fact that in many environments copper has good resistance, in a humid atmosphere it corrodes, which affects the appearance and properties of products made of it.

In this regard, the challenge is to reliably protect copper and its alloys from corrosion. For this, organic azole-based corrosion inhibitors (CI), such as benzotriazole (BTA) and 2mercaptobenzothiazole (2-MBT) are widely used [1-7]. In a number of studies, it was shown that salts of carboxylic acids and their compositions with silanes can be effective copper CIs [7-11]. Compared with azoles, these substances are less expensive and more environmentally friendly. Sodium oleate and oleyl sarcosinate (SOL and SOS, respectively) are especially effective [11]. At the same time, dicarboxylic acids and their salts have been studied relatively little, although interest in them as CIs of various metals in neutral media periodically arises [12-21]. Perhaps this is due to the assumption that due to the presence of two reactive carboxy groups in dicarboxylate molecules, their adsorption will be higher than in the case of monocarboxylates, and, therefore, they will exhibit higher protective properties.

As previously noted [19], despite the fact that the first studies of dicarboxylic acid salts as $\mathrm{CI}$ in neutral media were carried out more than half a century ago, they did not cause much interest. One of the reasons for this was probably the fact that CIs with general formula $\mathrm{NaOOC}\left(\mathrm{CH}_{2}\right)_{n} \mathrm{COONa}$ were studied, which often did not demonstrate advantages over monocarboxylic acids salts such as $\mathrm{H}_{3} \mathrm{C}\left(\mathrm{CH}_{2}\right)_{n} \mathrm{COONa}$. Dicarboxylates were primarily studied to protect low carbon steel and much less commonly to protect other metals. The results of A.D. Mercer [13], in which these dicarboxylates were found to possess not only drawbacks but also advantages over alkylmonocarboxylates, deserve attention. Later G.T. Hefter et al. [14] compared the corrosion inhibition efficiency of a copper rotating disk electrode in an aqueous solution containing $500 \mathrm{ppm} \mathrm{NaCl}$ and $100 \mathrm{ppm} \mathrm{NaHCO}_{3}$ by additives of $\alpha, \omega$-dicarboxylates and alkylmonocarboxylates (at $C_{\mathrm{in}} \leq 5 \mathrm{mM}$ ). As a criterion for the protective properties of carboxylates, they used the values of the polarization resistance of the metal calculated by the Stern-Geary equation. It turned out that at $n<3$, $\alpha, \omega$-dicarboxylates are significantly weaker copper CIs than similar alkyl carboxylates. Oxalate is not a CI, but rather accelerates copper corrosion even more strongly than iron corrosion. The authors associated this with the formation of a soluble strong complex with $\mathrm{Cu}(\mathrm{II})$, which, apparently, is formed not only in the case of malonate $(n=1)$, but also succinate $(n=2)$, although they already show inhibitory properties. Sodium glutarate $(n=3)$ is even a slightly better copper CI than butyl carboxylate, but only tridecandionate $(n=11)$ 
and other studied salts of higher $\alpha, \omega$-dicarboxylic acids $(n=12$ and 14) acquire the properties of highly effective CIs $(Z=98 \%)$. Note that this value is slightly larger than for higher alkyl carboxylates with $n=11,13$, and 17 , where it is 96,96 , and $97 \%$, respectively.

It was concluded that the complex dependence of $Z$ on the alkyl length in aliphatic carboxylates is associated not only with the adsorption of CI but also with their formation of micelles and complexes with the metal to be protected by these compounds. U. Rammelt et al. [16], who investigated the protection of low-carbon steel from corrosion in a neutral solution with salts of mono- and $\alpha, \omega$-dicarboxylic acids using various electrochemical methods, including EIS, concluded that azelate and sebacinate are adsorbed more weakly than nonanoate and decanoate. To explain this, they used the assumption of K. Aramaki and T. Shimur [15] that $\alpha, \omega$-dicarboxylates are adsorbed by two carboxy groups have a "loop-like" shape, which prevents them from being densely packed on a metal. In contrast, monoalkylcarboxylates, at least such as nonanoate and decanoate, are better ordered in the adsorption layer due to one "anchor" group and easily oriented hydrophobic alkyl. They found that a mixture of sebacinate and decanoate provides better steel protection, probably due to the formation of a denser adsorption film.

In this connection, salts of dicarboxylates in which a long hydrocarbon chain is not located between the carboxyls but is attached to one of the $\mathrm{CH}_{2}$ groups that bind them are of interest. An example of such compounds include alkenylsuccinic acids. It was recently shown [21] that, to protect aluminum alloys in aqueous solutions and in a humid atmosphere, sodium salts of alkenylsuccinic acids with 12-15 carbon atoms in the alkenyl radical contained in the industrial anticorrosive additive KAP-25 can be used.

The aim of this work is to identify the possibility of using the above salts of dicarboxylic acids as copper CIs in neutral media and to compare their effectiveness with that of other carboxylate CIs studied previously.

\section{Experimental}

All studies were performed on samples and electrodes made of M1 grade copper (99.9\% $\mathrm{Cu}$ ). Succinic acid was neutralized with an equivalent amount of $\mathrm{NaOH}$ to prepare a sodium succinate solution. Similarly, a CI was prepared from KAP-25 (TU 2499-080-050152072003) taking into account the acid number indicated in the product passport. A borate buffer solution ( $\mathrm{pH} 7.4$ ) containing $10 \mathrm{mmol} / \mathrm{L} \mathrm{NaCl}$ served as the background solution.

A cylindrical copper sample mounted in a Teflon holder was used as an electrode for electrochemical studies. The electrode working surface was the base of the cylinder with an area of $0.75 \mathrm{~cm}^{2}$. The electrode was ground and polished with different grades of emery paper, P600 and P1000 sequentially, then degreased with acetone.

Copper anodic polarization curves were recorded using an IPC-Pro MF potentiostat, in a three-electrode glass cell with the electrode space separated by a glass filter. A silver chloride reference electrode and a graphite auxiliary electrode were used. All potentials were converted to the normal hydrogen scale. The working electrode was placed in a cell 
containing $0.025 \mathrm{~L}$ of the background solution and kept for $15 \mathrm{~min}$ at $E=-0.60 \mathrm{~V}$ in order to reduce the primary copper oxide formed in air. After that, the potential was switched off, a CI was added, and after $15 \mathrm{~min}$, during which a quasi-stationary potential was established, the electrode was anodically polarized at a potential scan rate of $0.2 \mathrm{mV} / \mathrm{s}$.

For EIS measurements, we used M1 copper ( $\mathrm{Cu} 99.9 \%$, GOST 859-2014) cylindrical sample with a diameter $\varnothing=0.6 \mathrm{~cm}$, which was mounted with epoxy resin into a polypropylene holder so that its working surface was the base of the cylinder $\left(S_{\mathrm{Cu}}=\right.$ $0.28 \mathrm{~cm}^{2}$ ). The electrode was polished with different grades of emery paper up to P1000 paper, then degreased with acetone. All experiments were performed using the computerized electrochemical complex "Solartron Schlumberger" (United Kingdom) consisting of a potentiostat 1286 and a frequency response analyzer FRA 1250.

To record the spectrum, we used a glass cell with a volume $V=0.05 \mathrm{~L}$ with separated cathode and anode spaces. Electrochemical impedance spectra were obtained in the frequency range $f$ from $10 \mathrm{kHz}$ to $0.1 \mathrm{~Hz}$ with an alternating voltage amplitude of $10 \mathrm{mV}$. The working and auxiliary electrodes (a platinum grid with an area of $S_{\mathrm{Pt}}=20 \mathrm{~cm}^{2}$ ) were placed coaxially in the electrochemical cell. The potentials of the copper electrode were measured relative to a silver chloride electrode and converted to the normal hydrogen scale. The studies were carried out in $3.5 \% \mathrm{NaCl}$ solution with natural aeration.

A prepared sample was immersed in the solution without or with a CI, kept for $1 \mathrm{~h}$, and the spectrum was recorded at the corrosion potential. To determine the values of the equivalent electrical circuit (EEC) elements, the results were processed using the ZView program.

Corrosion tests were carried out in $0.5 \mathrm{~L}$ cells containing $50 \mathrm{ml}$ of water with a temperature of $60^{\circ} \mathrm{C}$. First, $30 \times 70 \mathrm{~mm}$ copper plates were polished on P1000 emery paper to a mirror finish and degreased with acetone. Then they were kept for $5 \mathrm{~min}$ in an aqueous CI solution with $t=60^{\circ} \mathrm{C}$. After that, the cell was closed with a lid, on which the samples were suspended so that they did not touch each other and the cell walls. Due to natural cooling of cells, the water vapor condensed on the samples. The cooled water was daily replaced with hot water. Simultaneously, the samples were examined to record the time until the first signs of copper corrosion appeared.

To toughen the test conditions in several experiments, copper samples after passivation treatment in a CI solution were first immersed for $10 \mathrm{~s}$ in an aqueous solution of 0.1 or $1 \mathrm{~g} / \mathrm{L} \mathrm{NaCl}$. The treated samples, after removal of the chloride solution drops from their surfaces, were placed in the cell to perform tests described above.

\section{Results and Discussion}

\section{Potentiodynamic studies}

Succinic acid anions, i.e. succinate ions, are very hydrophilic particles, as evidenced by the negative value of $\log D=-5.47$ (Table 1 ). Despite this, they exhibit surface activity even at a very low concentration of $C_{\text {in }} \geq 0.01 \mathrm{mmol} / \mathrm{L}$ (Figure 1). At first they are corrosive 
towards copper, which is expressed in a small increase in the passivation current density $i_{\mathrm{p}}$ and a decrease in the value of the local electrode depassivation potential, $E_{\mathrm{ld}}$. However, with an increase in $C_{\text {in }}$ to $0.05 \mathrm{mmol} / \mathrm{L}$, succinate becomes an inhibitor of the anodic dissolution of copper: the $i_{\mathrm{p}}$ value decreases and $E_{\mathrm{ld}}$ increases (by $0.25 \mathrm{~V}$ compared to the background solution).

The value of $\log D$ characterizes the hydrophobic/hydrophilic properties of anions or cations, i.e. takes into account the effect of the charge resulting from the dissociation or protonation of the corresponding organic molecules. It is calculated by the equation:

$$
\log D=\log R-\log \left[1+10\left(\mathrm{pH}-\mathrm{p} K_{\mathrm{a}}\right)\right],
$$

where $R$ is the distribution coefficient in the system of two immiscible liquids, wateroctanol [22]; $\log D$ is positive if an anion is hydrophobic and negative, if it is hydrophilic.

Table 1. The hydrophobicity and dissociation constants of monobasic and dibasic carboxylic acids calculated through the ChemAxon resource. ${ }^{\mathrm{a}}$

\begin{tabular}{cccc}
\hline Acid & $\log \boldsymbol{P}$ & $\mathbf{p} \boldsymbol{K}_{\mathbf{a}}$ & $\mathbf{L o g} \boldsymbol{D}$ \\
\hline Succinic acid & -0.40 & $3.55 ; 5.69$ & -5.47 \\
Tridecanoic acid & 4.92 & 4.95 & 2.51 \\
Stearic acid & 8.22 & 4.78 & 5.62 \\
Oleic acid & 6.78 & 4.99 & 4.40 \\
$\mathrm{CH}_{3}\left(\mathrm{CH}_{2}\right)_{4} \mathrm{CH}=\mathrm{CH}\left(\mathrm{CH}_{2}\right)_{5}-$ & 4.23 & 4.36 & -0.25 \\
$\mathrm{CHCH}_{2}(\mathrm{COOH})_{2}$ & & 4.39 & 1.61 \\
$\mathrm{CH}_{3}\left(\mathrm{CH}_{2}\right)_{5} \mathrm{CH}=\mathrm{CH}\left(\mathrm{CH}_{2}\right)_{7}-$ & 6.01 & & \\
$\mathrm{CHCH}_{2}(\mathrm{COOH})_{2}$ & & & \\
\hline
\end{tabular}

Unfortunately, an increase in $C_{\text {in }}$ to $0.10 \mathrm{mmol} / \mathrm{L}$ practically does not change the value of $E_{\mathrm{ld}}$. Its further increase is observed at $C_{\mathrm{in}}=4 \mathrm{mmol} / \mathrm{L}$ and is accompanied by a significant increase in $i_{\mathrm{p}}$, which indicates the formation of soluble $\mathrm{Cu}(\mathrm{I})$ complexes with succinate anions.

Unlike succinate, the sodium salts of alkenylsuccinic acids, which are part of KAP-25 (SKAP-25), are hydrophobic due to the presence of a carbon chain in the structure $(\log D$ about 0.5$)$. In this regard, even at their concentrations of $0.17 \mathrm{mmol}$, they begin to noticeably protect the copper surface (Figure 2), slowing down the active dissolution of the metal and increasing $E_{\mathrm{ld}}$.

\footnotetext{
${ }^{\mathrm{a}}$ The results of the study of hydrophobicity and dissociation constants of the studied acids, $\mathrm{p} K_{\mathrm{a}}$ from the ChemAxon resource (https://chemicalize.com) are presented. Since KAP-25 is a mixture, the constants are calculated for alkenylsuccinic acids with carbon chain lengths of 12 and 15 and a double bond in the 6 and 7 position, respectively. In this regard, for KAP-25, two values of $\log P$ and $\mathrm{p} K_{\mathrm{a}}$ values for their corresponding $\log D$ are presented. The values of $\log D$ were taken for $\mathrm{pH} 7.4$.
} 


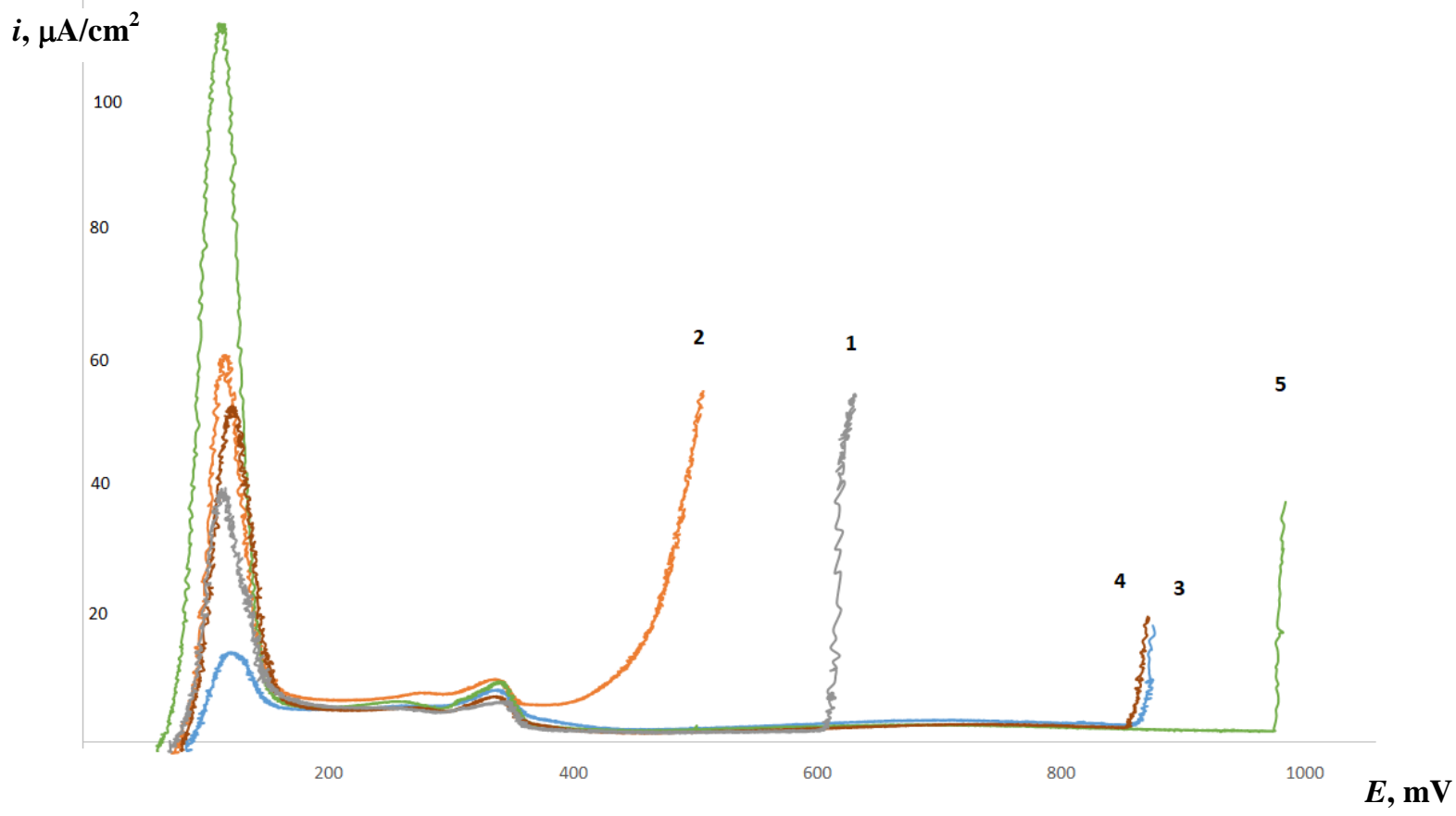

Figure 1. Copper anodic polarization curves in a borate buffer solution ( $\mathrm{pH} \mathrm{7.4)} \mathrm{containing}$ $10 \mathrm{mmol} / \mathrm{L} \mathrm{NaCl}$ without (1) and with the addition of sodium succinate (mmol/L): $2-0.01$, $3-0.05,4-0.10,5-4.0$.

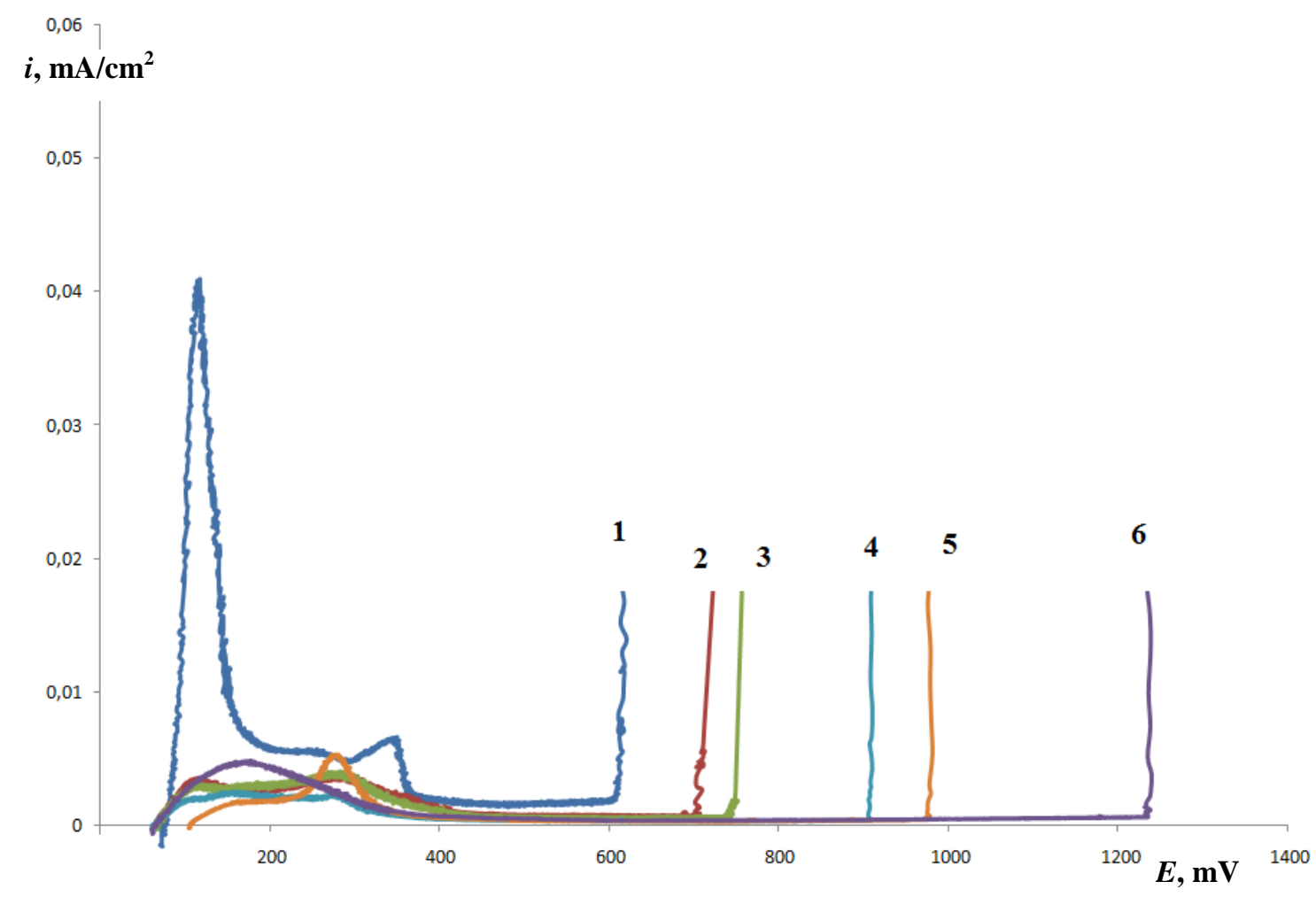

Figure 2. Copper anodic polarization curves in a borate buffer solution at $\mathrm{pH} 7.4$ containing $10 \mathrm{mmol} / \mathrm{L} \mathrm{NaCl}$ without (1) and with the addition of $\mathrm{KAP}-25$ sodium salts (in mmol): $2-0.17 ; 3-0.48 ; 4-1.7 ; 5-3.5 ; 6-7.0$. 
With an increase in $C_{\mathrm{in}}$, an improvement in the protective properties is noticeable: $E_{\mathrm{ld}}$ monotonically increases and reaches the value of the oxygen evolution potential at $7 \mathrm{mmol} / \mathrm{L}$.

However, when compared with the polarization curves obtained for sodium tridecanoate, i.e., an alkylcarboxylic acid salt with an alkyl length of $n_{\mathrm{c}}=12$ (for KAP-25, the alkylene chain has $\left.n_{\mathrm{c}}=12-15\right)$, it is clear that the monobasic acid salt shows the best result here: addition of $C_{\text {in }}=3.5 \mathrm{mmol} / \mathrm{L}$ to SKAP-25 is needed for shifting $E_{\text {ld }}$ to $1.0 \mathrm{~V}$, against $0.70 \mathrm{mmol} / \mathrm{L}$ in case of tridecanoate [23]. Apparently, this is due to the fact that the monobasic acid has a greater hydrophobicity $(\log D=2.97)$ than KAP-25 acids that have one more carboxy group, which dissociates in solution to give $\log D=-0.25$ to 1.61 (Table 1).

The presence of a double bond in these dicarboxylic acids also reduces their hydrophobicity, as indirectly indicated by a comparison of stearic and oleic acids (Table 1). According to the results of copper polarization measurements obtained in [23] in the same borate buffer containing $10 \mathrm{mmol} / \mathrm{L} \mathrm{NaCl}$, the shift of $E_{\mathrm{ld}}$ to $0.96 \mathrm{~V}$ in the presence of sodium oleate occurs at $C_{\text {in }}=3.1 \mathrm{mmol} / \mathrm{L}$. Therefore, despite the significantly higher hydrophobicity of the anion of oleic acid compared to those of the alkenylsuccinic acids contained in KAP-25, the effectiveness of these CIs is similar. It can be assumed that the presence of two reactive $\mathrm{COO}^{-}$groups and their favorable arrangement in alkenylsuccinic acid anions at least partially compensate for their lower hydrophobicity.

\section{Corrosion studies}

Recently, the efficacy of SKAP-25 and sodium oleate, one of the best inhibitors of local depassivation of aluminum alloy AD-31, was noted in [21]. In this regard, tests were carried out on the protective ability of SKAP-25 in a humid atmosphere that does not contain corrosive chloride salts. The results of these tests, in which the corrosiveness of the medium was created only by daily condensation of moisture on samples pre-treated by immersing them for $5 \mathrm{~min}$ in hot $\left(60^{\circ} \mathrm{C}\right) \mathrm{CI}$ solutions at $C_{\text {in }}=8$ or $16 \mathrm{mmol} / \mathrm{L}$, are presented in Table 2. For comparison, it also presents the results of similar tests of such well-known carboxylate-type CIs as sodium tridecanoate [23] and sodium oleate [11].

It is easy to see that in tests of passive copper in a humid atmosphere, preliminary passivation in an SKAP-25 solution is more effective than a similar treatment in a sodium tridecanoate solution. This is not consistent with the conclusions drawn from the results of electrochemical measurements on copper in solutions of these CIs. Perhaps the reason is that the discussed anodic polarization curves of copper were recorded in a chloridecontaining buffer solution, whereas there were no chlorides on the surface of the passive film formed by the $\mathrm{CI}$ in the corrosion tests. In this regard, we carried out additional accelerated tests, which were performed with immersion of samples in $0.1 \% \mathrm{NaCl}$ solution after passivation with CI solutions. As expected, such samples corrode more rapidly, as it was recently shown in [24]. Whereas, when tested in a humid atmosphere, the advantage of 
the studied dicarboxylic acid salts over sodium tridecanoate is doubtless, SKAP-25 shows a significantly weaker protective effect in more drastic tests than the monobasic acid salt with a similar chain length. It can be assumed that SKAP-25 is very sensitive to the corrosive action of chlorides; therefore, it is necessary to find the possibility of enhancing its protective properties in these media.

Table 2. Test results of copper samples previously passivated in aqueous CI solutions in a humid atmosphere with daily condensation of moisture on the samples.

\begin{tabular}{|c|c|c|c|c|}
\hline \multirow[b]{2}{*}{ Corrosion inhibitor (CI) } & \multirow{2}{*}{$\underset{\mathrm{mmol} / \mathrm{L}}{C_{\mathrm{in}}}$} & \multicolumn{3}{|c|}{ The time until the first corrosion damage, days } \\
\hline & & without $\mathrm{NaCl}$ & $\begin{array}{l}\text { After immersion } \\
\text { in } 0.1 \mathrm{~g} / \mathrm{L} \mathrm{NaCl}\end{array}$ & $\begin{array}{l}\text { After immersion } \\
\text { in } 1.0 \mathrm{~g} / \mathrm{L} \mathrm{NaCl}\end{array}$ \\
\hline \multirow{2}{*}{ Sodium tridecanoate $\left(n_{\mathrm{c}}=12\right)$} & 8 & $19 \pm 0.5[23]$ & & \\
\hline & 16 & $24 \pm 0.5[23]$ & $21 \pm 0.5$ & $14 \pm 0.5$ \\
\hline \multirow{2}{*}{ SKAP-25 $\left(n_{\mathrm{c}}=\mathrm{C}_{12}-\mathrm{C}_{15}\right)$} & 8 & $40 \pm 0.5$ & $12 \pm 0.5$ & $5 \pm 0.5$ \\
\hline & 16 & $72 \pm 0.5$ & $18 \pm 0.5$ & $6 \pm 0.5$ \\
\hline \multirow{2}{*}{ Sodium oleate $\left(n_{\mathrm{c}}=\mathrm{C}_{17}\right)$} & 2 & $18 \pm 0.5[11]$ & $15 \pm 0.5$ & $11 \pm 0.5$ \\
\hline & 16 & $>41$ & $22 \pm 0.5$ & $16 \pm 0.5$ \\
\hline
\end{tabular}

\section{EIS studies}

To this end, we studied the inhibitory effect of SKAP-25 and a mixed CI based on it by the EIS method in a concentrated chloride solution. The impedance measurements of SKAP25 in $3.5 \% \mathrm{NaCl}$ (Figure 3a) showed that for all the $C_{\text {in }}$ studied, it is adequately described by the Randles-Erschler equivalent circuit (EC) (Figure 4a) where CPE is a constant phase element characterizing the capacity of the double electric layer, $R_{\mathrm{t}}$ is the charge transfer resistance, and $W$ is the Warburg diffusion impedance. CPE is related to the true capacity of the double layer by the equation:

$$
C_{\mathrm{dl}}=\left(\mathrm{CPE} \cdot R_{\mathrm{t}}\right)(1 / n) / R_{\mathrm{t}},
$$

where $n$ is a power factor.

In this case, a typical hodograph (see the inset in Figure 3a) is a part of a semicircle that quickly turns into an inclined line (diffusion impedance) already in the high-frequency region. An increase in $C_{\mathrm{SKAP}-25}$ practically does not affect the shape of the curves.

To improve the inhibitory properties of sodium salts of alkenylsuccinic acids in the presence of chlorides, the sodium salt of 2-mercaptobenzothiazole (S2-MBT) was used. S2-MBT is known for its ability to form a protective complex with monovalent copper [26]. First, we consider the behavior of copper in $3.5 \% \mathrm{NaCl}$ in the presence of this CI (Figure $3 \mathrm{~b}$ ). At $C_{\mathrm{S} 2-\mathrm{MBT}}=1.0 \mathrm{mM}$, the impedance is also described by the Randles-Ershler $\mathrm{EC}$, but as $C_{\mathrm{S} 2 \mathrm{MBT}}$ grows, the hodograph changes and a pronounced high-frequency semicircle is observed starting from $1.5 \mathrm{mM}$ of S2-MBT. This indicates the formation of a 
coating and is described by the corresponding EC (Figure 4b): the $R_{\mathrm{c}}-C_{\mathrm{c}}$ chain characterizing the properties of this layer is added to the Randles-Erschler impedance.
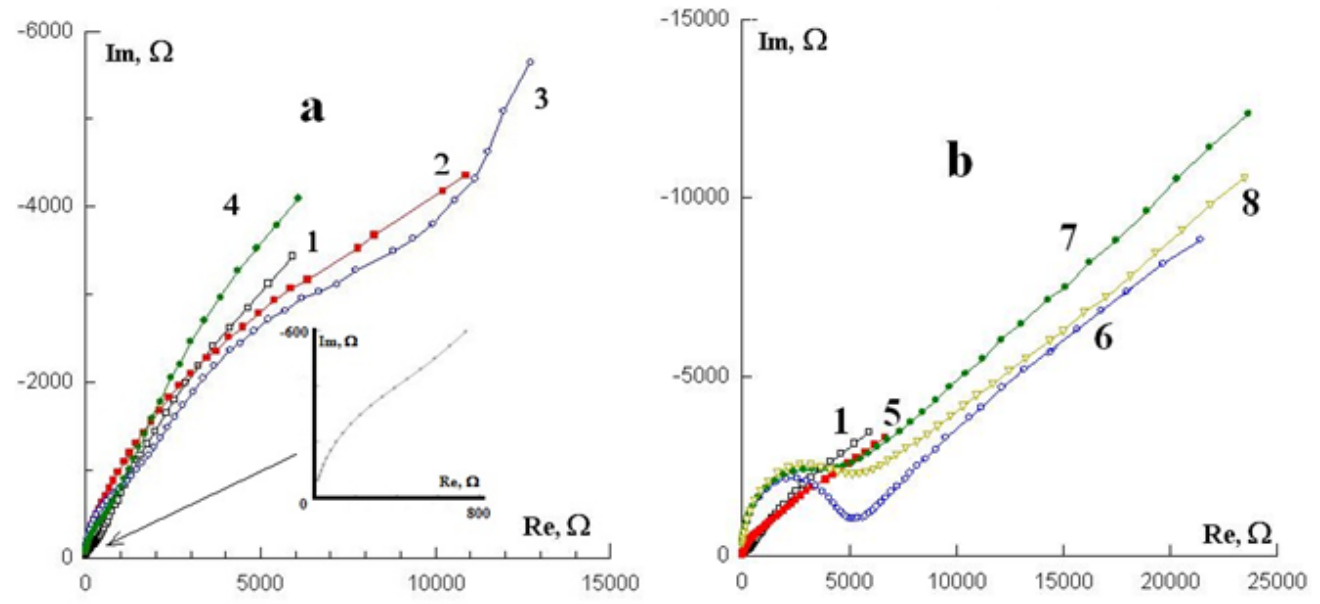

Figure 3. Impedance of $\mathrm{M} 1$ copper in 3.5\% NaCl with additives (in $\mathrm{mM}$ ) SKAP-25 (a) or S2MBT (b). 1 - without additives, 2 - 3 SKAP-25, 3 - 5 SKAP-25, 4 - 8 SKAP-25, 5 - 1 S2MBT, 6 - 1.5 S2-MBT, 7 - 2 S2-MBT, 8 - 4 S2-MBT.
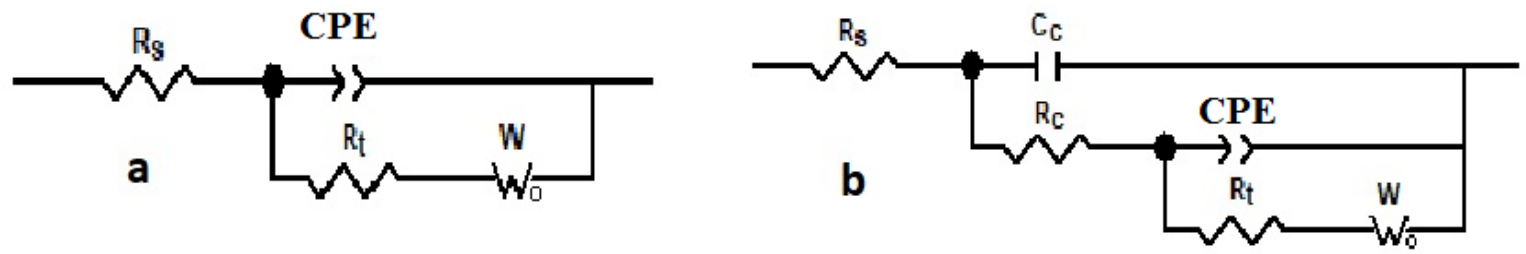

Figure 4. $\mathrm{EC}$ of $\mathrm{M} 1$ copper in 3.5\% NaCl: $\mathrm{a}$ - Randles-Erschler, $\mathrm{b}$ - coated electrode.
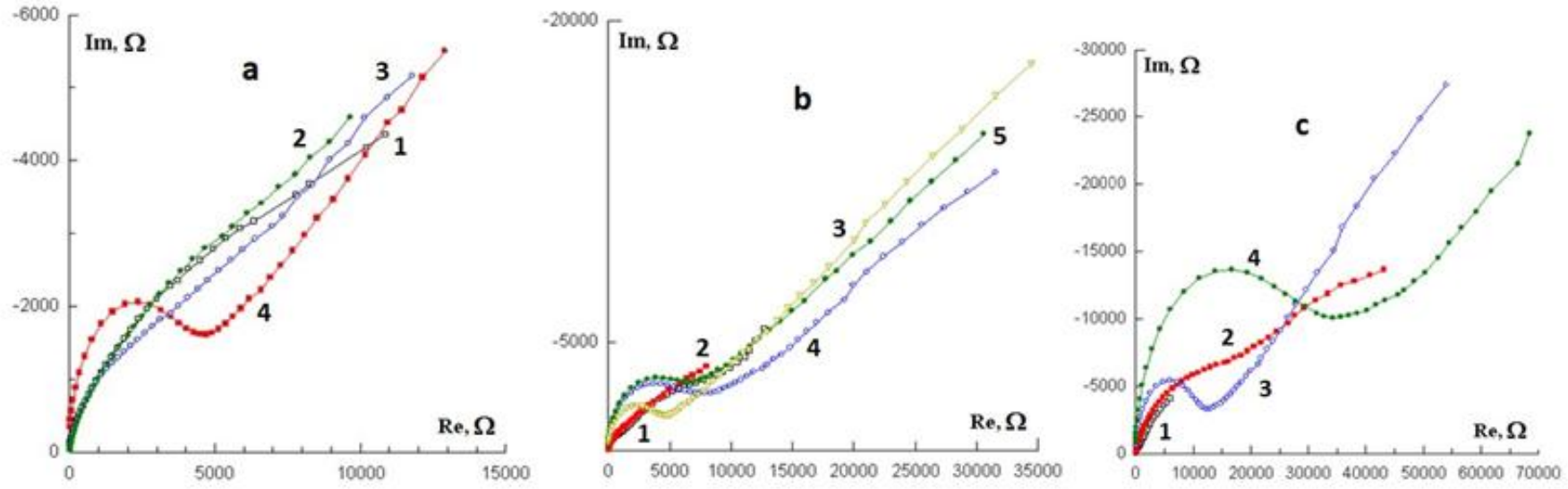

Figure 5. Niquist plot of $\mathrm{M} 1$ copper in $3.5 \% \mathrm{NaCl}$ with additives (in $\mathrm{mM}$ ):

$\mathrm{a}-3$ mM SKAP-25 + S2-MBT (mM): $1-0.0 ; 2-0.6 ; 3-1.0 ; 4-1.5$

$\mathrm{b}-5$ mM SKAP-25 + S2-MBT (mM): $1-0.0 ; 2-1.0 ; 3-1.5 ; 4-2.0 ; 5-2.5$

c -8 mM SKAP-25 + S2-MBT (mM): $1-0.0 ; 2-1.0 ; 3-1.5 ; 4-4.0$. 
Mixtures of SKAP-25 and S2-MBT behave similarly (Figure 5). At small $C_{\mathrm{S} 2-\mathrm{MBT}}$, the Randles-Ershler impedance is observed, and as the concentration of S2-MBT increases and the coating is formed, a semicircle appears in the diagram. The calculation of the resistance value of the coating $R_{\mathrm{c}}$, which in this system can characterize the degree of protection of the metal from corrosion, shows that in the general case there is a mutual strengthening of the inhibitory properties of the mixture components. Both S2-MBT addition at fixed $C_{\mathrm{SKAP}-25}$ and SKAP-25 addition at fixed $C_{\mathrm{S} 2 \mathrm{MBT}}$ promote $R_{\mathrm{c}}$ growth (Table 3). It can be seen at $C_{\mathrm{S} 2 \mathrm{MBT}}=1.5 \mathrm{mM}$ (Figure 6a), but it is especially pronounced at $C_{\mathrm{S} 2 \mathrm{MBT}}=2.0 \mathrm{mM}$ (Figure $6 \mathrm{~b}$ ).

Table 3. The effect of CI composition on the $R_{\mathrm{c}}$ value obtained by calculating the impedance of M1 copper in $3.5 \% \mathrm{NaCl}$.

\begin{tabular}{cc}
\hline SKAP-25 $(\mathbf{m M})+\mathbf{S} 2-\mathbf{M B T}(\mathbf{m M})$ & $\boldsymbol{R}_{\mathbf{c}}, \mathbf{k O h m}$ \\
\hline $0.0+1.5$ & 5.10 \\
$0.0+2.0$ & 5.91 \\
$0.0+4.0$ & 6.18 \\
$3.0+1.5$ & 5.03 \\
$3.0+2.0$ & 9.03 \\
$5.0+1.5$ & 9.36 \\
$5.0+2.0$ & 10.32 \\
$5.0+2.5$ & 8.02 \\
$8.0+1.5$ & 12.66 \\
$8.0+2.0$ & 69.15 \\
$8.0+4.0$ & 33.92 \\
\hline
\end{tabular}
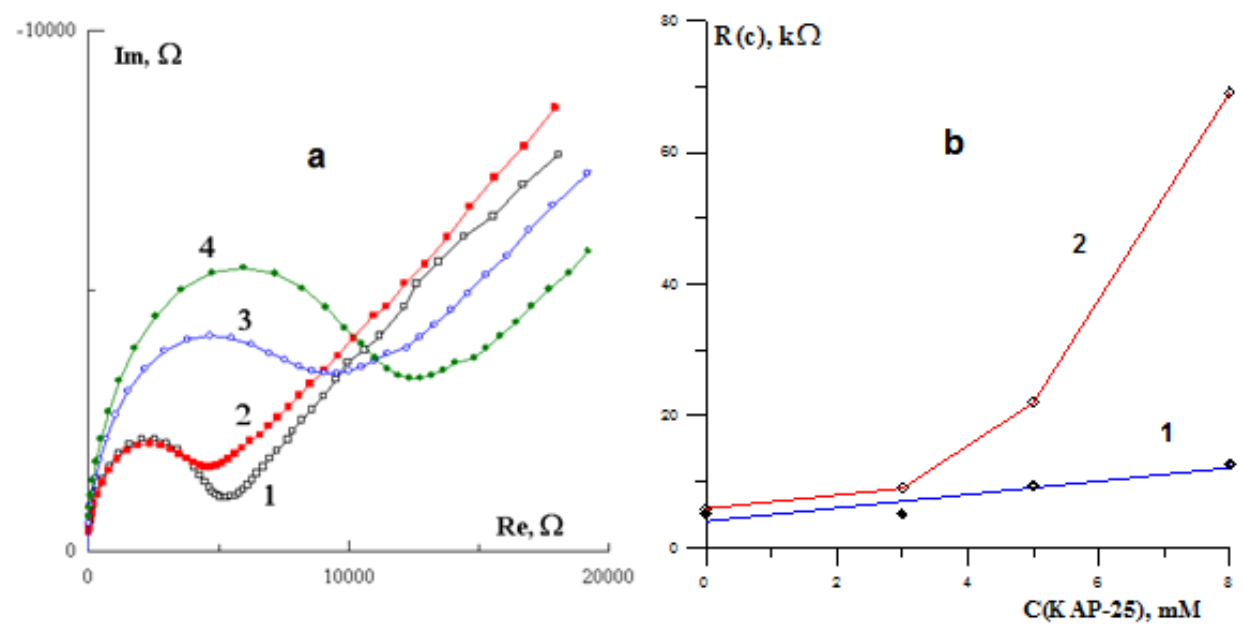

Figure 6. a: Nyquist plot obtained on copper in an aqueous solution containing $3.5 \% \mathrm{NaCl}+$ 1.5 mM S2-MBT without (1) and with the addition of SKAP-25 (in $\mathrm{mM}$ ): $2-3 ; 3-5 ; 4-8$. b: The effect of $C_{\mathrm{SKAP}-25}$ on the value of $R_{\mathrm{c}}$ for $C_{\mathrm{S} 2 \mathrm{MBT}}, \mathrm{mM}: 1-1.5 ; 2-2.0$. 


\section{Conclusion}

1. Sodium succinate is able to inhibit the copper anodic dissolution in neutral aqueous solutions, although it stabilizes the passive state of the metal only at relatively high concentrations $\left(C_{\mathrm{in}} \geq 0.05 \mathrm{mM}\right)$. Its disadvantage as a copper $\mathrm{CI}$ is that is dangerous to increase $C_{\text {in }}$, which, along with improved copper protection from local depassivation, increases the current density of copper dissolution in the active region, probably due to the formation of soluble complex compounds with copper cations.

2. The sodium salts of alkenylsuccinic acids contained in the KAP-25 anticorrosive additive (TU 2499-080-05015207-2003) are much more effective in inhibiting the dissolution of copper. These acids and their anions significantly surpass sodium succinate in hydrophobicity due to the presence of an alkenyl with 12-15 carbon atoms. The suppression of copper active dissolution with a mixture of sodium alkenyl succinates (SKAP-25) occurs at lower concentrations than, for example, in case of sodium laurate. However, SKAP-25 is less effective in stabilization of the passive state than the more hydrophobic anions of tridecanoic or oleic acids.

3. Copper passivation in aqueous carboxylates solutions can prevent atmospheric corrosion for a very long period. In this case, SKAP-25 is essentially more effective then sodium tridecanoate and is close to sodium oleate in this respect. However, if chlorides are deposited on a passive surface, the protective properties of SKAP-25 decrease noticeably and passivation even with sodium tridecanoate becomes more effective than with SKAP25.

4. In order to search for an additive that improves the protective properties of SKAP-25 in chloride-containing media, the prospects of S2-MBT, which is capable of forming hardly soluble complex compounds with copper, were studied. Using the EIS method, it was proved that small additives of S2-MBT to an aqueous $3.5 \% \mathrm{NaCl}$ solution sharply increase the protective properties of SKAP-25 even in such a corrosive environment.

\section{References}

1. Yu.I. Kuznetsov and L.P. Kazansky, Physicochemical aspects of metal protection by azoles, Russ. Chem. Rev., 2008, 77, no. 3, 219-232. doi: 10.1070/RC2008v077n03ABEH003753

2. N.K. Allam, A.A. Nazeer and E.A. Ashour, A review of the effects of benzotriazole on the corrosion of copper and copper alloys in clean and polluted environments, J. Appl. Electrochem., 2009, 39, 961-969. doi: 10.1007/s10800-009-9779-4

3. M. Finšgar and I. Milošev, Inhibition of copper corrosion by 1,2,3-benzotriazole: A review, Corros. Sci., 2010, 52, 2737-2749. doi: 10.1016/j.corsci.2010.05.002

4. M. Petrović Mihajlović and M.M. Antonijević, Copper Corrosion Inhibitors. Period 2008-2014. A Review, Int. J. Electrochem. Sci., 2015, 10, 1027-1053. 
5. Yu.I. Kuznetsov, Organic corrosion inhibitors: Where are we now? A review. Part II. Passivation and the role of chemical structure of carboxylates, Int. J. Corros. Scale Inhib., 2016, 5, no. 4, 282-318. doi: 10.17675/2305-6894-2016-5-4-1

6. O.A. Goncharova, A.Yu. Luchkin, N.N. Andreev, Yu.I. Kuznetsov, N.P. Andreeva and S.S. Vesely, Protection of copper by treatment with hot vaporous of octadecylamine, 1,2,3-benzotriazole and their mixtures, Mater. Corros., 2018, 70, no. 1, 161-168. doi: $\underline{10.1002 / \mathrm{maco} .201810366}$

7. Yu.I. Kuznetsov, Triazoles as a class of multifunctional corrosion inhibitors. A review. Part I. 1,2,3-Benzotriazole and its derivatives. Copper, zinc and their alloys, Int. J. Corros. Scale Inhib., 2018, 7, no. 3, 271-307. doi: 10.17675/2305-6894-2018-7-3-1

8. E. Rocca, G. Bertrand, C. Rapin and J.C. Labrune, Inhibition of copper aqueous corrosion by non-toxic linear sodium heptanoate: mechanism and ECAFM study, $J$. Electroanal. Chem., 2001, 503, 133-140. doi: 10.1016/S0022-0728(01)00384-9

9. P. Wang, R. Qiua, D. Zhanga, Z. Lina and B. Hou, Fabricated super-hydrophobic film with potentiostatic electrolysis method on copper for corrosion protection, Electrochim. Acta, 2010, 56, 517-522. doi: 10.1016/j.electacta.2010.09.017

10. Yu.I. Kuznetsov, I.A. Kuznetsov and N.P. Andreeva, The formation of adsorption layers on copper from aqueous solutions of sodium laurate and their protective effect in a humid atmosphere, Korroz.: Mater., Zashch. (Corrosion: Materials, Protection), 2017, 4, 26-32 (in Russian).

11. M.O. Agafonkina, Yu.I. Kuznetsov and N.P. Andreeva, Inhibitor Properties of Carboxylates and Their Adsorption on Copper from Aqueous Solutions, Russ. J. Phys. Chem. A, 2015, 89, no. 6, 1070-1076. doi: 10.1134/S0036024415060023

12. J.E.O. Mayne, The mechanism of the inhibition of the corrosion of iron in the $\mathrm{pH}$ range 5-13, In Proceed. of the $4^{\text {th }}$ Europ. Symp. on Corros. Inhib., Ferrara (Italy), 1975, 1, $1-5$.

13. A.D. Mercer, The properties of carboxilates as corrosion inhibitors for steel and other metals in neutral aqueous solutions, In Proceed. of the $5^{\text {th }}$ Europ. Symp. on Corros. Inhib., Ferrara (Italy), 1980, 2, 563-581.

14. G.T. Hefter, N.A. North and S.H. Tan, Organic corrosion inhibitors in neutral solutions. Part 1. Inhibition of steel, copper and aluminum by straight chain carboxylates, Corrosion, 1997, 53, 657-667. doi: 10.5006/1.3290298

15. K. Aramaki and T. Shimura, Self-assembled monolayers of carboxylate ions on passivated iron for preventing passive film breakdown, Corros. Sci., 2004, 46, $313-$ 328. doi: 10.1016/S0010-938X(03)00156-2

16. P. Taheri, J. Wielant, T. Hauffmanc, J.R. Flores, F. Hannour, J.H.W. de Wit, J.M.C. Mol and H. Terryn, A comparison of the interfacial bonding properties of carboxylic acid functional groups on zinc and iron substrates, Electrochim. Acta, 2011, 56, no. 4, 1904-1911. doi: 10.1016/j.electacta.2010.10.079 
17. U. Rammelt, S. Köhler and G. Reinhard, Electrochemical characterization of the ability of dicarboxylic acid salts to the corrosion inhibition of mild steel in aqueous solutions, Corros. Sci., 2011, 53, 3515-3520. doi: 10.1016/j.corsci.2011.06.023

18. D. Lahem, M. Poelman, F. Atmani and M.G. Olivier, Synergistic improvement of inhibitive activity of dicarboxylates in preventing mild steel corrosion in neutral aqueous solutions, Corros. Eng., Sci. Technol., 2012, 47, 463-471. doi: 10.1179/1743278212Y.0000000030

19. Yu.I. Kuznetsov, Organic corrosion inhibitors: where are we now? A review. Part II. Passivation and the role of chemical structure of carboxylates, Int. J. Corros. Scale Inhib., 2016, 5, 282-318. doi: 10.17675/2305-6894-2016-5-4-1

20. G. Chan-Rosado and M.A. Pech-Canul, Influence of native oxide film age on the passivation of carbon steel in neutral aqueous solutions with a dicarboxylic acid, Corros. Sci., 2019, 153, 19-31. doi: 10.1016/j.corsci.2019.03.033

21. A.M. Semiletov, Yu.I. Kuznetsov and A.A. Kolesnikova, O zashchite ot atmosfernoi korrozii alyuminievogo splava AD31 antikorrozionnoi prisadkoi KAP-25, Korroz.: Mater., Zashch. (Corrosion: Materials, Protection), 2019, no. 12, 17-22 (in Russian).

22. R.A. Scherrer and S.M. Howard, Use of distribution coefficients in quantitative structure-activity relationships, J. Med. Chem., 1977, 20, no. 1, 53-58. doi: $\underline{10.1021 / \mathrm{jm} 00211 \mathrm{a} 010}$

23. Yu.I. Kuznetsov, I.A. Kuznetsov and N.P. Andreeva, Adsorption of sodium tridecanoate on copper from aqueous solutions and copper protection from atmospheric corrosion, Int. J. Corros. Scale Inhib., 2018, 7, no. 4, 648-656. doi: 10.17675/23056894-2018-7-4-11

24. A.A. Chirkunov, D.O. Chugunov and Yu.I. Kuznetsov, The effect of vinyltrimethoxysilane on the effectiveness of passivating films on a phosphonatemodified steel surface, Korroz.: Mater., Zashch. (Corrosion: Materials, Protection), 2019, 9, 14-18 (in Russian).

25. L.P. Kazansky, I.A. Selyaninov and Yu.I. Kuznetsov, Adsorption of 2mercaptobenzothiazole on copper surface from phosphate solutions, Appl. Surf. Sci., 2012, 258, 6807-6813. doi: 10.1016/j.apsusc.2012.03.097 